\title{
The Virtual Resistance Control Strategy for HVRT of Doubly Fed Induction Wind Generators Based on Particle Swarm Optimization
}

\author{
Zhen Xie and Xue Li \\ School of Electric Engineering and Automation, Hefei University of Technology, Hefei 230009, China \\ Correspondence should be addressed to Zhen Xie; ppsd2003xie@sina.com
}

Received 17 January 2014; Revised 9 May 2014; Accepted 25 May 2014; Published 10 July 2014

Academic Editor: Marcelo M. Cavalcanti

Copyright (c) 2014 Z. Xie and X. Li. This is an open access article distributed under the Creative Commons Attribution License, which permits unrestricted use, distribution, and reproduction in any medium, provided the original work is properly cited.

Grid voltage swell will cause transient DC flux component in the doubly fed induction generator (DFIG) stator windings, creating serious stator and rotor current and torque oscillation, which is more serious than influence of the voltage dip. It is found that virtual resistance manages effectively to suppress rotor current and torque oscillation, avoid the operation of crowbar circuit, and enhance its high voltage ride through technology capability. In order to acquire the best virtual resistance value, the excellent particle library (EPL) of dynamic particle swarm optimization (PSO) algorithm is proposed. It takes the rotor voltage and rotor current as two objectives, which has a fast convergence performance and high accuracy. Simulation and experimental results verify the effectiveness of the virtual resistance control strategy.

\section{Introduction}

Many studies have focused on the impact of grid voltage sags [1-4] on wind turbine generators and low voltage ridethrough (LVRT) technology, but insufficient attention has been given to the influence of grid voltage swell on the same generators and high voltage ride-through (HVRT) technology. In wind power systems, grid voltage swell may be caused by single-phase line-to-ground faults, sudden removal of large loads, and the use of a large capacitor compensator [5, 6]. The commonly used DFIG [7], which is connected to the grid through the converter, follows the principle of grid voltage sag faults. When grid voltage swells, its transient process also causes the current or voltage to swell in the stators and rotors of the DFIG. To avoid these problems and protect the converter, wind turbine generators can be automatically taken off-grid and perform grid-connected operation after failure recovery. However, this off-grid strategy no longer meets the standards of the grid connection of modern large-scale wind power generation [8]. Most wind power integration standards require the LVRT ability of wind farms; the expansion of wind power generation capacity and the improvement of integration standards will soon make HVRT ability a prerequisite for wind farms. The wind power integration standards of E.ON in Germany require the HVRT ability of wind turbine generators: when grid voltage increases to $1.2 \mathrm{pu}$, wind turbine generators should maintain long-term fault ridethrough and absorb a certain amount of reactive power in high-voltage conditions. Moreover, the ratio between reactive current and the change rate of grid voltage should be $2: 1$. This standard is the control requirement of reactive compensation in high-voltage conditions. Australia first established HVRT standards for grid-connected wind turbine generators [9]. When grid voltage increases to $130 \%$ of the nominal voltage, wind turbine generators should maintain fault ride-through in $60 \mathrm{~ms}$ and provide a sufficiently high fault recovery current. This standard requires the capability of resisting and running through the high voltage of wind turbine generators.

DFIG can achieve HVRT by increasing hardware circuits and improving system control (Figure 1). A chopper circuit on the DC side of the converter was used by [5] to prevent voltage on the DC side from increasing because of the reverse flow of the grid side converter energy triggered by a grid voltage swell. Reference [10] proposed that the series resistance of current transformers on the rotor side could prevent rotor overcurrent, thus preventing the rotor side converter from 


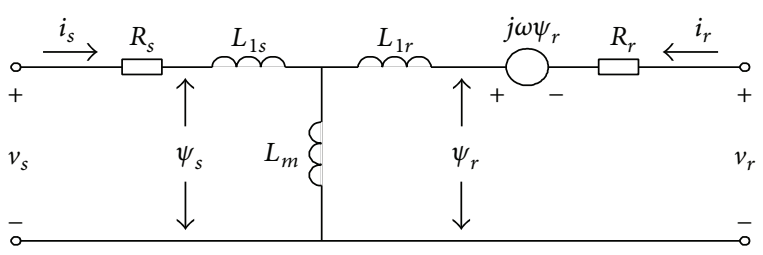

FIGURE 1: DFIG equivalent circuit at static stator-oriented reference frame.

losing control over the generator because crowbar resistance will be used if a grid fault occurs. This series resistance can also continuously provide reactive power to the grid during the fault and reduce torque ripple. References [6, 11] examined and compared the static synchronous compensator (STATCOM) and dynamic voltage restorer (DVR) schemes during a grid voltage swell. In the DVR scheme, generator voltage is maintained by compensating for the voltage difference between normal and fault conditions. In the STATCOM scheme, grid voltage decreases by controlling the reactive current injected into the power grid. Especially when grid impedance is relatively low, both schemes significantly increase the cost of using the whole set of hardware. The STATCOM scheme is uneconomical because it requires current far stronger than the rated current of wind turbine generators. The enhanced controlling strategy of the DFIG under a grid voltage swell is proposed in [12]: decoupling control in fault conditions is achieved by establishing an accurate model of the dynamic process of the DFIG rotor field current. This model considers the compensation dosage of the rotor field current change on the basis of the conventional controller. Proportional-integral control should be used in normal operations and vector hysteresis control in grid faults [13].

In the HVRT of DFIG, converter overcurrent can be avoided by using the crowbar on the rotor side, thus rapidly increasing the generator torque and generating an uncontrollable output of active and reactive power when the grid voltage swells. To solve these problems and ensure the excellent HVRT of the DFIG, this study analyzes the electromagnetic transient course of the DFIG under the grid voltage swell and examines the control strategy of active damping in the rotor converter according to the passive damping scheme of the series resistance of the generator rotor $[14,15]$. Thus, rotor overvoltage is managed when the grid voltage swells, the rotor overcurrent is maximally controlled, and the HVRT of the DFIG is improved. To acquire the best virtual resistance value, this paper adopts the EPL of dynamic PSO algorithm for the multiobjective optimization design of parameters. It takes the rotor voltage and rotor current as two objectives for the integrated optimization. As the result of the multiple iterations, the algorithm can be caught in local optimum. Thus, the algorithm is improved in this paper, which is on the basis of the excellent library and dynamic improvement. This makes the algorithm more suitable for the dynamic changes of the actual cases. Therefore, the local optimum of PSO algorithm can not only be avoided, but also the speed and accuracy of the optimum can be improved.

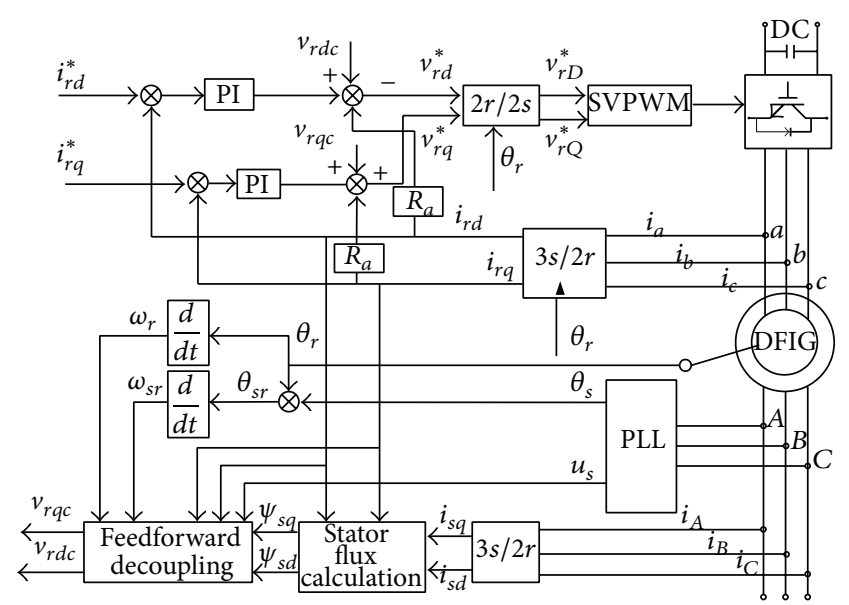

FIGURE 2: Block diagram of the DFIG control system based on virtual resistance.

Simulation and experimental results confirm the feasibility of this damping scheme.

\section{Dynamic Analysis of DFIG during Grid Voltage Swell}

DFIG equivalent circuit is shown in Figure 1 to analyze the dynamic behavior during grid voltage swell. For simplicity, all rotor variables are converted to stator side and linear magnetic circuits are assumed [16]. With the application of motor convention, the DFIG model can be expressed as

$$
\begin{gathered}
\vec{v}_{s}=R_{s} \vec{i}_{s}+\frac{d}{d t} \vec{\psi}_{s}, \\
\vec{v}_{r}=R_{r} \vec{i}_{r}+\frac{d}{d t} \vec{\psi}_{r}-j \omega_{r} \vec{\psi}_{r}, \\
\vec{\psi}_{s}=L_{s} \vec{i}_{s}+L_{m} \vec{i}_{r}, \\
\vec{\psi}_{r}=L_{m} \vec{i}_{s}+L_{r} \vec{i}_{r} .
\end{gathered}
$$
follows:

The symbols and their corresponding meanings are as
$\vec{v}$ : voltage vector;
$\vec{i}$ : current vector;
$\omega_{r}:$ rotor electrical speed;
$\vec{\psi}$ : flux vector;
$R$ : resistance;
$L$ : inductance.

Subscripts $r$ and $s$ are the rotor and stator, respectively. The rotor voltage can be calculated from (2) as follows:

$$
\vec{v}_{r}=\frac{L_{m}}{L_{s}}\left(p-j \omega_{r}\right) \vec{\psi}_{s}+\left[R_{r}+\sigma L_{r}\left(p-j \omega_{r}\right)\right] \vec{i}_{r},
$$

where $\sigma=1-L_{m}^{2} / L_{s} L_{r}$. 
Under normal condition, the rotor voltage term induced by the stator flux is expressed as

$$
\vec{v}_{r 0}=j \omega_{s l} \frac{L_{m}}{L_{s}} \vec{\psi}_{s}=s \frac{L_{m}}{L_{s}} V_{s e} e^{j \omega_{s} t},
$$

where $\omega_{s l}=\omega_{s}-\omega_{r}$ and $s$ is the $\operatorname{sip}\left(s=\omega_{s l} / \omega_{s}\right)$ and $V_{s e}$ is the stator voltage amplitude.

The rotor voltage at rotor terminal generated by the converter is expressed as

$$
\vec{v}_{r}=\frac{L_{m}}{L_{s}} s \vec{v}_{s}+\left[R_{r}+\sigma L_{r}\left(p-j \omega_{r}\right)\right] \vec{i}_{r}
$$

At $t=t_{0}$, a fault appears in the grid. The corresponding stator side voltage is expressed as

$$
\begin{gathered}
\vec{v}_{s}\left(t<t_{0}\right)=V_{s e} e^{j \omega_{s} t}, \\
\vec{v}_{s}\left(t \geq t_{0}\right)=(1+q) V_{s e} e^{j \omega_{s} t},
\end{gathered}
$$

where $q$ is the grid voltage swell ratio. If the resistance $R_{s}$ is neglected, the steady-state stator flux is proportional to the voltage:

$$
\begin{gathered}
\vec{\psi}_{s}\left(t<t_{0}\right)=\frac{V_{s e}}{j \omega_{s}} e^{j \omega_{s} t}, \\
\vec{\psi}_{s}\left(t \geq t_{0}\right)=(1+q) \frac{V_{s e}}{j \omega_{s}} e^{j \omega_{s} t} .
\end{gathered}
$$

The stator flux under grid voltage swell is

$$
\vec{\psi}_{s}\left(t \geq t_{0}\right)=(1+q) \frac{V_{s e}}{j \omega_{s}} e^{j \omega_{s} t}-q \frac{V_{s e}}{j \omega_{s}} e^{j \omega_{s} t_{0}} e^{-\left(t-t_{0}\right) / \tau_{s}},
$$

where $\tau_{s}=\sigma L_{s} / R_{s}$.

The stator flux of (10) can be divided into forced flux and natural flux. The forced flux is proportional to the grid voltage and rotates at synchronous speed. The natural flux is a transient flux which guarantees that no discontinuity appears in the stator flux during grid voltage swell. The natural flux is proportional to the grid voltage swell ratio and does not rotate. The time constant of stator winding decreases exponentially the amplitude of the natural flux to zero.

If $t_{0}=0$ is assumed, the induced voltage in rotor reference frame during grid voltage swell can be obtained by substituting (10) in the first term of the right hand of (5) (neglecting the term $1 / \tau_{s}$ due to its low value):

$$
\vec{v}_{r 0}=\frac{L_{m}}{L_{s}} V_{s e}\left[s(1+q) e^{j \omega_{s l} t}+(1-s) q e^{-j \omega_{r} t} e^{-\left(t-t_{0}\right) / \tau_{s}}\right] .
$$

Each component of the stator flux induces a corresponding component. A small component proportional to the slip is first induced by the forced flux. The small component rotates at slip frequency and achieves some Hertz. The second component induced by natural flux is important because it is proportional to $1-s$. In addition, the second component rotates at rotor electrical speed $\omega_{r}$.

\section{HVRT Control Strategy of DFIG}

Virtual impedance control strategy is used to enhance HVRT capability and suppress the oscillation of DFIG during grid voltage swell [17].

3.1. Stability Analysis of the DFIG System. Using stator flux as state variables, rotor current and stator voltage as input variables, stator flux state equation can be expressed as

$$
\begin{gathered}
\frac{d}{d t} \psi_{s q}=-\frac{R_{s}}{L_{s}} \psi_{s q}-\omega_{s} \psi_{s d}+\frac{L_{m}}{L_{s}} R_{s} i_{r q}+u_{s}, \\
\frac{d}{d t} \psi_{s d}=-\frac{R_{s}}{L_{s}} \psi_{s d}+\omega_{s} \psi_{s q}+\frac{L_{m}}{L_{s}} R_{s} i_{r d} .
\end{gathered}
$$

The characteristic equation is expressed as

$$
\lambda^{2}+2 \frac{R_{s}}{L_{s}} \lambda+\frac{R_{s}^{2}}{L_{s}^{2}}+\omega_{s}^{2}=0
$$

The damping factor $\xi$ and natural oscillation frequency $\omega_{n}$ are

$$
\begin{gathered}
\xi=\frac{R_{s}}{\omega_{n} L_{s}}, \\
\omega_{n}=\sqrt{\frac{R_{s}^{2}}{L_{s}^{2}}+\omega_{s}^{2}} .
\end{gathered}
$$

Given the relatively low stator resistance of megawatt generators, DFIG have the feature of underdamping. The system is prone to oscillation when the grid voltage swells because its natural oscillation frequency is close to the grid frequency. Therefore, system damping control, including both passive and active damping controls, should be considered. Thus, the virtual resistance control strategy was employed to increase the system damping and improve the dynamic HVRT performance of DFIG.

3.2. Passive Damping Control Strategy. In a DFIG electromagnetic transient process motivated by a grid voltage swell, the rotor inducts strong back electromotive force (EMF) once the grid voltage swells because the rotor resistance and leakage impedance of the MW DFIG are relatively low. This strong EMF causes rotor overcurrent. Therefore, passive damping control is introduced; that is, dynamic series resistance is allocated to the side of the generator rotor. When the grid voltage swells, the passive damping of the dynamic series resistance of this generator rotor efficiently increases the system damping, reduces the peak oscillation of the rotor current, decreases the time constant of the rotor circuit, and quickly attenuates the rotor current. However, introducing a dynamic resistance increases system loss and reduces system efficiency, thus further complicating the resistance design. Therefore, a control algorithm that imitates the dynamic resistance (i.e., active damping control) should be considered. 


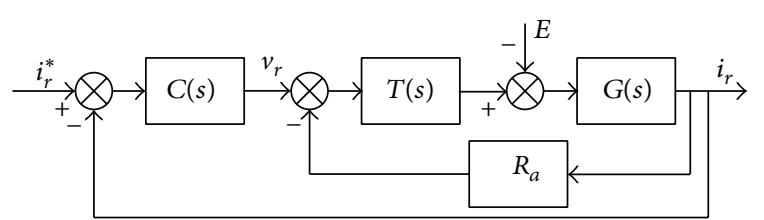

FIGURE 3: Block diagram of the current control system based on virtual resistance.

3.3. Virtual Resistance Control Strategy. To address the shortcomings of the practical dynamic resistance, active damping control based on virtual resistance can be adopted under a grid voltage swell to increase system resistance and improve the HVRT of the DFIG. A structural chart of the DFIG active damping control based on virtual resistance is shown in Figure 2.

For the analysis, the rotor side voltage can be reexpressed as

$$
\begin{gathered}
v_{s}=\left(R_{r}+R_{s} \frac{L_{m}^{2}}{L_{s}^{2}}\right) i_{r}+\sigma L_{r} \frac{d}{d t} i_{r}+j \omega_{s l} \sigma L_{r} i_{r}+E, \\
E=\frac{L_{m}}{L_{s}} \psi_{s}-\frac{L_{m}}{L_{s}}\left(\frac{R_{s}}{L_{s}}+j \omega_{r}\right) \psi_{s},
\end{gathered}
$$

where $E$ is the back electromotive force, which is a disturbance component for the rotor current control loop. Virtual resistance control strategy is used to reduce the time constant of the rotor current control loop, improve its dynamic response, and inhibit the effect of the disturbance on the dynamic performance of the rotor current. The rotor current control loop with virtual resistance control strategy is shown in Figure 3.

The rotor current closed loop controlled object transfer function $G(s)$ can be expressed as

$$
\begin{gathered}
G(s)=\frac{i_{r}(s)}{v_{r}(s)}=\frac{K_{g}}{T_{g} s+1}, \\
T_{g}=\frac{\sigma L_{r}}{\left(R_{r}+L_{m}^{2} R_{s} / L_{s}^{2}\right)}, \\
K_{g}=\frac{1}{\left(R_{r}+L_{m}^{2} R_{s} / L_{s}^{2}\right)} .
\end{gathered}
$$

The switching frequency of the rotor side converter is usually high; thus, the delay of inertia can be neglected to simplify the analysis:

$$
T(s)=K_{t} .
$$

Assume that the virtual resistance is equal to $R_{a}$; the rotor current closed loop controlled object transfer function can then be obtained using (16) and (17), as shown in Figure 3:

$$
G^{\prime}(s)=\frac{i_{r}(s)}{v_{r}(s)}=\frac{K_{g} K_{t}}{T_{g} s+1+R_{a} K_{g} K_{t}} .
$$

After the introduction of virtual resistance when (16) and (18) are compared, the time constant of the rotor current closed loop is reduced by $1+R_{a} K_{g} K_{t}$ times.
The PI controller of the rotor current loop is designed by the internal model principle; before the introduction of virtual resistance the transfer function is expressed as

$$
C(s)=\frac{K_{c} T_{g} s+K_{c}}{K_{t} K_{g} s},
$$

where $K_{c}$ is the bandwidth of the rotor current closed loop.

After the introduction of virtual resistance, the PI controller transfer function is expressed as

$$
C^{\prime}(s)=\frac{K_{c} T_{g} s+K_{c}+R_{a} K_{g} K_{t} K_{c}}{K_{t} K_{g} s} .
$$

Before the introduction of virtual resistance, the rotor current closed loop transfer function is expressed as

$$
G_{p}(s)=\frac{i_{r}(s)}{i_{r}^{*}(s)}=\frac{s}{s+K_{c}} .
$$

After the introduction of virtual resistance, the rotor current closed loop transfer function is expressed as

$$
G_{p}^{\prime}(s)=G_{p}(s) .
$$

Before the introduction of virtual resistance, the disturbance transfer function is expressed as

$$
G_{E I}(s)=\frac{i_{r}(s)}{E(s)}=\frac{K_{g} s}{\left(s+K_{c}\right)\left(T_{g} s+1\right)} .
$$

After the introduction of virtual resistance, the disturbance transfer function is expressed as

$$
G_{E I}^{\prime}(s)=\frac{i_{r}(s)}{E(s)}=-\frac{K_{g} s}{\left(s+K_{c}\right)\left(T_{g} s+1+R_{a} K_{g} K_{t}\right)}
$$

from (16), the following expression is obtained:

$$
G(s)=\frac{i_{r}(s)}{v_{r}(s)}=\frac{1}{\sigma L_{r} s+R_{r}+\left(L_{m}^{2} / L_{s}^{2}\right) R_{s}} ;
$$

from (18), the following expression is obtained:

$$
G^{\prime}(s)=\frac{i_{r}(s)}{v_{r}(s)}=\frac{K_{t}}{\sigma L_{r} s+R_{r}+\left(L_{m}^{2} / L_{s}^{2}\right) R_{s}+K_{t} R_{a}} .
$$

From (25) and (26), the introduction of the feedback coefficient $R_{a}$ is equivalent to series resistance $K_{t} R_{a}$ in the rotor circuit of the DFIG. The equivalent circuit of the rotor based on virtual resistance can be shown in Figure 4 .

It is known that regulating virtual resistance can change the dynamic response of the rotor current control loop during grid voltage swell. Figure 5 is bode graph before and after the introduction of virtual resistance. Compared to nonvirtual resistance strategy, in the low frequency region, active damping strategy has better inhibitory characteristic on the disturbance. In the high frequency region, both have the same disturbance inhibitory characteristic. Figure 6 is the step response of the disturbance transfer function 


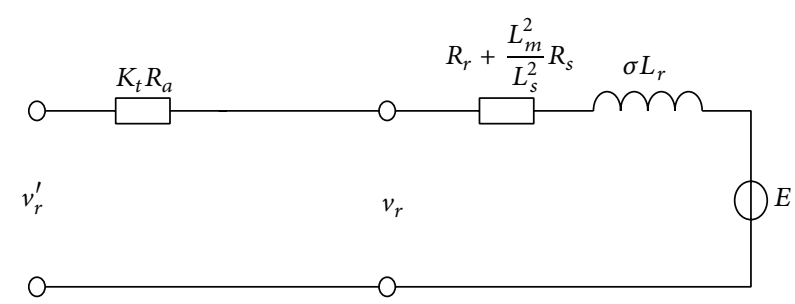

FIgURE 4: The rotor equivalent circuit based on virtual resistance.
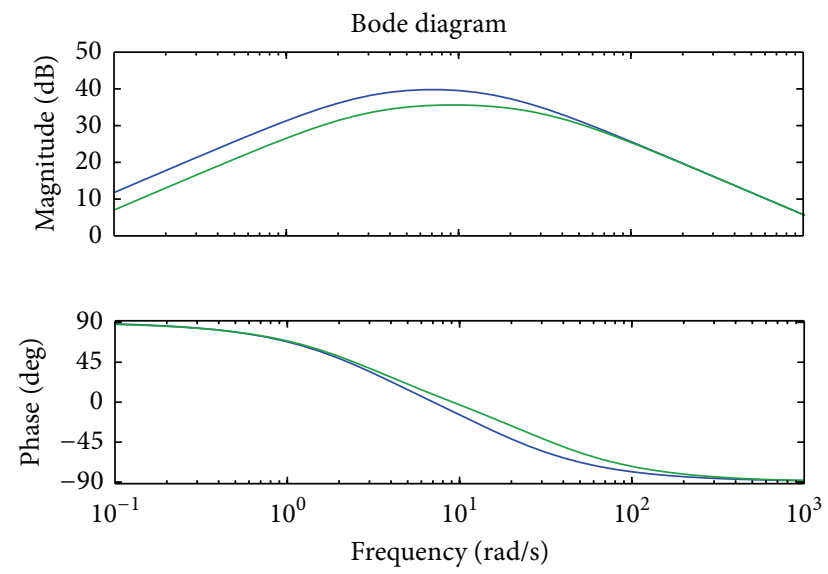

__ Without virtual resistance

FIGURE 5: Bode graph on disturbance with and without active damping strategy.

with and without virtual resistance, compared to nonvirtual resistance strategy, the overshoot was obviously inhibited by the virtual resistance strategy under step load disturbance, which can improve the capability of disturbance suppression under grid voltage fluctuations. Figure 7 is the root locus of the disturbance transfer function with and without virtual resistance; after the introduction of virtual resistance, the system root is near the real axis, which can increase the system damping and suppress the oscillation of the system.

\section{The Selection of Virtual Resistance}

4.1. The Establishment of Objective Function. The rotor current objective function is as follows:

$$
\begin{gathered}
f_{1}\left(R_{a}\right)=i_{d q}, \\
i_{d q}=\sqrt{i_{r d n}^{2}+i_{r q n}^{2}} \quad(n=1,2,3,4),
\end{gathered}
$$

where

$$
\begin{gathered}
i_{r d 1}=-\frac{L_{m} \omega_{\text {slip }} \psi_{s q 0}}{L_{s}\left(\sigma R_{r}+R_{a}\right)}, \quad i_{r q 1}=\frac{L_{m} \omega_{\text {slip }} \psi_{s d 0}}{L_{s}\left(\sigma R_{r}+R_{a}\right)}, \\
i_{r d 2}=-\frac{L_{m} \omega_{\text {slip }}\left(\psi_{s d 0}-\psi_{s d 2}\right)}{L_{s}\left(\sigma R_{r}+R_{a}\right)},
\end{gathered}
$$

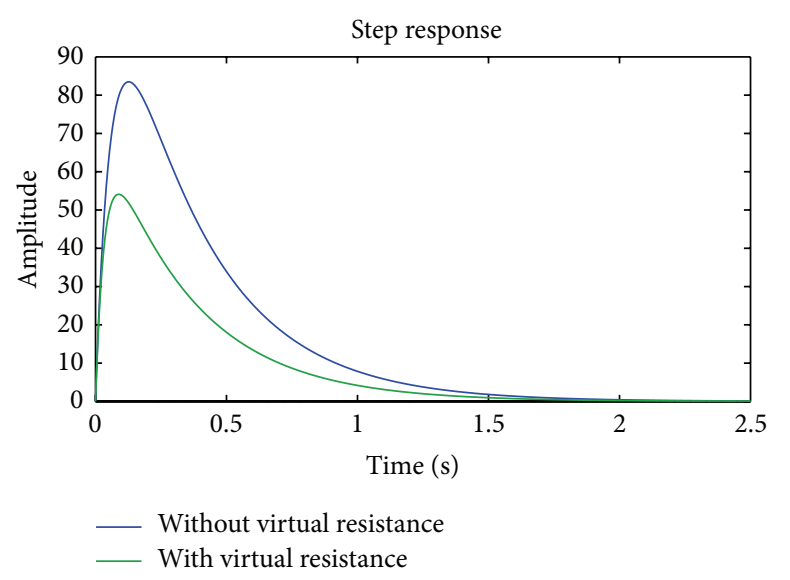

FIGURE 6: Step response of the disturbance transfer function with and without virtual resistance.

$$
\begin{gathered}
i_{r q 2}=-\frac{L_{m} \omega_{\text {slip }}\left(\psi_{s q 0}-\psi_{s q 2}\right)}{L_{s}\left(\sigma R_{r}+R_{a}\right)}, \\
i_{r d 3}=\frac{L_{m} \omega_{r}\left[b \cos \left(\omega_{s} t\right)-a \sin \left(\omega_{s} t\right)\right] e^{-\sigma t}}{n L_{s}\left[(d-\sigma)^{2}+\omega_{s}^{2}\right]}, \\
i_{r q 3}=\frac{L_{m} \omega_{r}\left[a \cos \left(\omega_{s} t\right)+b \sin \left(\omega_{s} t\right)\right] e^{-\sigma t}}{n L_{s}\left[(d-\sigma)^{2}+\omega_{s}^{2}\right]},
\end{gathered}
$$

$i_{r d 4}=\frac{L_{m} \omega_{r} a e^{-\sigma t}}{n L_{s}\left[(d-\sigma)^{2}+\omega_{s}^{2}\right]}, \quad i_{r q 4}=\frac{L_{m} \omega_{r} b e^{-\sigma t}}{n L_{s}\left[(d-\sigma)^{2}+\omega_{s}^{2}\right]}$,

where $m=\sigma L_{r}, n=\left(\sigma R_{r}+R_{a}\right), d=m / n, a=(d-\sigma)\left(\psi_{s d 0}-\right.$ $\left.\psi_{s d 2}\right)-\omega_{s}\left(\psi_{s q 0}-\psi_{s q 2}\right)$, and $b=(d-\sigma)\left(\psi_{s d 0}-\psi_{s d 2}\right)+\omega_{s}\left(\psi_{s q 0}-\right.$ $\left.\psi_{s q 2}\right) \cdot i_{r o}$ is the initial state of current. $\alpha_{s}$ and $\alpha_{d q}$ represent the closed loop and the open loop bandwidth of the control model. $\sigma$ denotes the damping time constant. $L_{m}, L_{s}$, and $L_{r}$ are the mutual inductance and the stator and rotor selfinductances. $\omega_{s}$ is the synchronous speed. $\psi_{s d 0}$ and $\psi_{s q 0}$ are the steady state stator flux of $d$ and $q$ axes prior to the voltage drop. $\psi_{s d 2}$ and $\psi_{s q 2}$ are the steady state stator flux of $d$ and $q$ axes after the voltage drop.

The rotor voltage objective function is as follows:

$$
\begin{gathered}
f_{2}\left(R_{a}\right)=v_{d q}, \\
v_{d q}=\sqrt{v_{d n}^{2}+v_{q n}^{2}} \quad(n=1,2,3),
\end{gathered}
$$

where

$$
\begin{gathered}
v_{r d 1}=-\frac{\omega_{\text {slip }} R_{a} L_{m}}{n L_{s}} \psi_{s q 0}, \quad v_{r q 1}=-\frac{\omega_{\text {slip }} R_{a} L_{m}}{n L_{s}} \psi_{s d 0}, \\
v_{r d 2}=\frac{\omega_{\text {slip }} R_{a} L_{m}\left(\psi_{s q 0}-\psi_{s q 2}\right)}{n L_{s}}, \\
v_{r q 2}=\frac{\omega_{\text {slip }} R_{a} L_{m}\left(\psi_{s d 0}-\psi_{s d 2}\right)}{n L_{s}},
\end{gathered}
$$




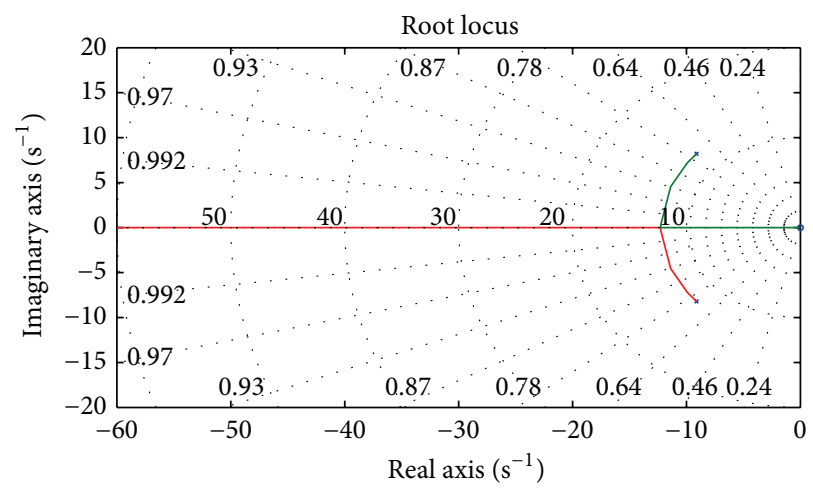

(a) Without virtual resistance

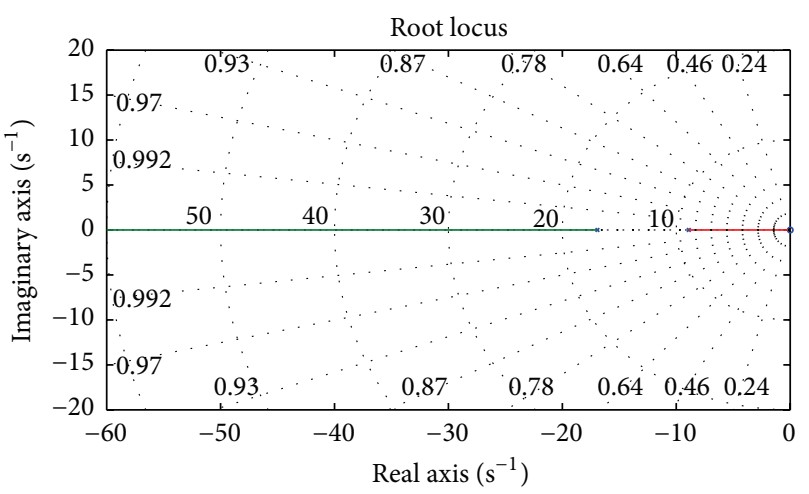

(b) With virtual resistance

Figure 7: The root locus of the disturbance transfer function with and without virtual resistance.

$$
\begin{aligned}
& v_{r d 3}=\frac{\omega_{r} R_{a} L_{m}\left[b \cos \left(\omega_{s} t\right)-a \sin \left(\omega_{s} t\right)\right]}{n L_{s}\left[(d-\sigma)^{2}+\omega_{s}^{2}\right]} e^{-\sigma t}, \\
& v_{r q 3}=\frac{\omega_{r} R_{a} L_{m}\left[a \cos \left(\omega_{s} t\right)+b \sin \left(\omega_{s} t\right)\right]}{n L_{s}\left[(d-\sigma)^{2}+\omega_{s}^{2}\right]} e^{-\sigma t},
\end{aligned}
$$

where $m, a$, and $b$ are the same as the above description. $\omega_{\text {slip }}$ is the slip frequency, and $\omega_{\text {slip }}=s \cdot \omega_{s} ; s$ denotes the slip.

Obviously, there are two objective functions, the current and voltage. This paper adopts the method of important objective and satisfied constraints to simply the objective functions. Let the current objective function as the first optimization goal when the grid voltage swell is less than $0.3 \mathrm{pu}$. Let the voltage objective function as the first goal when the grid voltage swell is greater than $0.3 \mathrm{pu}$. Meanwhile, make the satisfaction function as a constraint condition. The constraint value is described as follows:

$$
\begin{gathered}
\max f_{1}\left(R_{a}\right) \leq \alpha_{1}, \\
\max f_{2}\left(R_{a}\right) \leq \alpha_{2}, \\
J=\beta_{1} f_{1}\left(R_{a}\right)+\beta_{2} f_{2}\left(R_{a}\right),
\end{gathered}
$$

where $\alpha_{1}, \alpha_{2}$ are the satisfaction function values, and equal to the maximum current allowed to flow through the converter. When the swell amplitude reduces, $\beta_{1}$ decreases and $\beta_{2}$ increases. Thus we can seek out the best solution.

4.2. The EPL of Dynamic PSO Algorithm. In particle swarm optimization (PSO) algorithm, the particles are optimized by changing the speed and position of the particles. As the algorithm proceeds, the effective distance between particles will be diminished, and the particle concentration increased. Then particles with small Euclidean distance will iterate repeatedly, prone to premature convergence and lead the PSO algorithm to the local best solution, which affect the speed of convergence and the precision of algorithm. Hence, it is necessary to adjust the particle concentration in PSO algorithm. The particle concentration is associated with the degree of similarity between particles. The degree of similarity between particles is decided by two aspects: the Euclidean distance between two particles: $d\left(x_{i}, x_{j}\right)$, and the difference between their fitness function value: $\mid$ fit $\left(x_{i}\right)-$ fit $\left(x_{j}\right) \mid$. If $x_{i}=$ $\left(x_{i 1}, x_{i 2}, \ldots, x_{i m}\right)$ and $x_{j}=\left(x_{j 1}, x_{j 2}, \ldots, x_{j m}\right)$ are noted as two particles of PSO algorithm, the Euclidean distance between them is

$$
d\left(x_{i}, x_{j}\right)=\sqrt{\sum_{k=1}^{m}\left(x_{i k}-x_{j k}\right)^{2}} .
$$

When $d\left(x_{i}, x_{j}\right) \leq D$ and $\left|\operatorname{fit}\left(x_{i}\right)-\operatorname{fit}\left(x_{j}\right)\right| \leq f$, the two particles $x_{i}$ and $x_{j}$ can be regarded as similarity. $D$ is the threshold value of distance and $f$ is the threshold value of fitness. The concentration of the particle $i$ is defined as follows:

$$
a_{i}=\frac{n}{N},
$$

where $n$ is the particle number which is similar to $i ; N$ is the total particle number in the particle swarm.

The probability of retained particles is

$$
P\left(x_{i}\right)=\frac{\text { fit }\left(x_{i}\right) / a_{i}}{\sum_{j=1}^{N}\left[\text { fit }\left(x_{j}\right) / a_{i}\right]} .
$$

The probability of retained particles is determined by the concentration and the fitness of particle $i$. The probability of retained particles is lower if the particles concentration is larger, and the probability is higher if the fitness value is larger. This method controls the evolution of the high particle concentration and also prevents the occurrence of "premature" phenomenon. Concurrently, the particles with larger fitness value can evolve fully, which can keep the population diversity.

The particles with larger fitness value inevitably contain some key information. Hence, this paper adopts probabilistic method to keep some excellent particles, and then these excellent particles iterate into the next generation with large probability. It not only avoids the blind search of the algorithm but also can improve the convergence speed. 
The steps to establish the excellent particle library (EPL) are as follows: after each iteration of particle swarm optimization (PSO), the PSO can produce two best solutions (denoted as fitness) which are $P_{\text {ibest }}$ denoted as pbest and $G_{\text {best }}$ denoted as gbest. $P_{i \text { best }}$ is the fitness which has been achieved till current iteration, and $G_{\text {best }}$ is the global best solution. Let the capacity of the EPL be $Q$, make the $P_{\text {ibest }}$ sort in terms of the fitness of the particles from small to large, and select $G_{\text {best }}$ and the first $Q-1$ of $P_{\text {ibest }}$ to replace the original excellent memory particles in the EPL. Thus in processing a new generation of particles, the particles of smaller fitness in PSO will be replaced by more excellent particles. Hence, the fitness of the whole particle groups is improved, and the convergence speed of the algorithm is accelerated.

In a static environment, on the basis of local and global optimal solutions, the particles can finally find the optimal value in the solution space through iterative formula. But because the rotor voltage and current of doubly fed induction generator change at any time, the dynamic improvement is introduced to adapt to the changes of the current environment.

The achievement of dynamic PSO is as follows: first of all, the solution space is divided into $n_{1}$ uniform subspaces. In the subspaces, $n_{2}$ particles sensitive to the environment are initialized randomly. Then the fitness of sensitive particles denoted as $f_{i}$ is calculated separately in every iteration, and the difference of the adjacent two particles denoted as $\Delta f_{i}$ is calculated by (33). In the end, all the absolute values of $\Delta f_{i}$ are summed denoted as $F$ by (34). Consider

$$
\begin{gathered}
\Delta f_{i}=f_{i}(k+1)-f_{i}(k), \\
F=\sum_{i=1}^{n}\left|\Delta f_{i}\right| \quad\left(n=n_{1} \times n_{2}\right) .
\end{gathered}
$$

If $F$ is not equal to 0 , it can be thought that the external environment has been changed. We can set a threshold value denoted as $F_{o}$. When $F$ is greater than $F_{o}$, the dynamic response is triggered. The response mechanism is used to reinitialize the position and velocity of particles proportionally, which is described as follows:

$$
\text { If } F>F_{o}, \text { then }\left\{\begin{array}{l}
v(i)=\operatorname{rand}(M) \times v_{\max } \\
x(i)=\operatorname{rand}(M) \times x_{\max }
\end{array},\right.
$$

where $\operatorname{rand}(M)$ are $M$ dimensions random numbers in $[0,1]$. $x_{i}=\left(x_{i 1}, x_{i 2}, \ldots, x_{i M}\right)$ and $v_{i}=\left(v_{i 1}, v_{i 2}, \ldots, v_{i M}\right)$ are denoted as the position and velocity of the $i$ th particle selected from the population of the new initialization. $M$ denotes the dimension, $X_{\max }$ denotes the maximum position, and $V_{\max }$ denotes the maximum velocity.

4.3. Steps of the EPL of Dynamic PSO Algorithm. Probability to be selected is related to the concentration of the particles. Both the current and voltage in the objective function are to find the minimum values, so opposite to (34), it is replaced by (38) as follows:

$$
p\left(x_{i}\right)=\frac{1 /\left(a_{i} \text { fit }\left(x_{i}\right)\right)}{\sum_{j=1}^{N}\left[1 /\left(a_{i} \text { fit }\left(x_{j}\right)\right)\right]} .
$$

The detailed algorithm simulation steps are as follows.
Step 1. Initialize the particle parameters, which include the searching space, the particle numbers $N$, initial position, and velocity. All of them are random numbers; meanwhile the position and velocity are between 0 and 1, considering that the resistance cannot be negative.

Step 2. Establish the EPL according to (31) to calculate the fitness of each particle and acquire the local optimal solution $P_{i \text { best }}$ and the global optimal solution $G_{i \text { best }}$ of the particle $x_{i}$. Put $G_{i \text { best }}$ and the smaller fitness value into the EPL as excellent particles. Judge whether the particle completes the iterations, and if it does, the iteration will end.

Step 3. Supposing the EPL is made up of $N_{1}$ particles and random initialization $M$ sensitive particles, calculate the fitness of sensitive particle $i$ by (31) and $F$ by (36). If $F>F 1$, then reinitialize according to (37) and to Step 2.

Step 4. The velocity and position of each particle are updated by the following equation:

$$
\begin{gathered}
v_{i d}^{t+1}=\omega v_{i d}^{t}+c_{1} \times \operatorname{rand}_{1}(\cdot) \times\left(p_{i d}-x_{i d}^{t}\right) \\
+c_{2} \times \operatorname{rand}_{2}(\cdot) \times\left(p_{g d}-x_{g d}^{t}\right), \\
x_{i d}^{t+1}=x_{i d}^{t}+v_{i d}^{t+1},
\end{gathered}
$$

where $\omega$ is used as an inertia weight, and the initial value of $\omega$ is set within the range $[0,1] . \omega$ is updated by the following equation:

$$
\omega=\omega_{\max }-\frac{\omega_{\max }-\omega_{\min }}{T} \cdot t
$$

where $\omega_{\max }$ and $\omega_{\min }$ denote the maximum inertia weight and the minimum. $T$ is the maximum number of iterations and $t$ is the current iteration number at the present number.

Step 5. Regulate the particle concentration. Select $N$ particles from the $(N+M)$ particles generated in Steps 1 and 2. The probability of each particle is selected according to (38).

Step 6. Use the excellent particles in EPL to replace the particles of larger fitness. In this way a new generation of particle swarm is generated, and then go to Step 2 .

Step 7. End the iteration.

\section{Results and Analysis}

Supposing the initial voltage of the stator $U_{s}=690 \mathrm{~V}$, the initial voltage of the rotor $U_{r}=220 \mathrm{~V}$, when the voltage swell is 0.3 , and the rotor speed is $1800 \mathrm{r} / \mathrm{min}$, the fitness curves of the ordinary PSO algorithm, the changing inertia weight PSO algorithm, and the EPL of dynamic PSO algorithm are as Figure 8.

From Figure 8, the ordinary PSO algorithm converges finally, but the convergence speed is slow and the convergence time is long. Comparing with the ordinary PSO algorithm, the changing inertia weight PSO algorithm increases the 


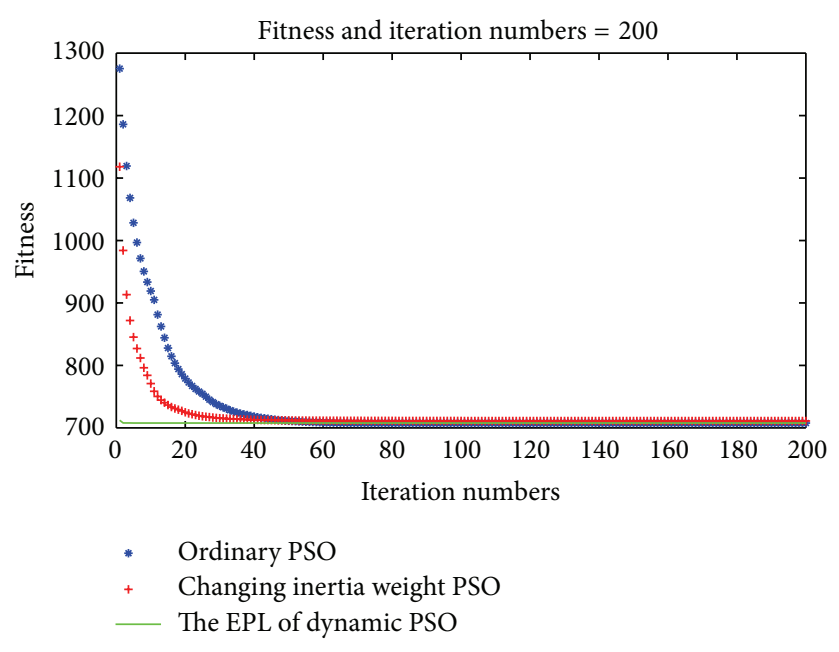

FIgURE 8: Fitness curve.

convergence speed of the algorithm and shortens the convergence time. The excellent particle library of dynamic PSO algorithm is on the establishment of excellent particle library, and a dynamic optimization is added. Considering that the rotor voltage changes along with the voltage swell, the new particles which can respond to the external environment change are used in the EPL of dynamic PSO algorithm. Thus local optimum of the algorithm will be avoided because of the similarity and unnecessary search between particles, and the convergence speed and convergence precision of the algorithm are guaranteed.

Through the comparison of three kinds of PSO algorithm, this paper put forward the EPL of the dynamic PSO algorithm by modifying the distance between the particles, adjusting the particle concentration, avoiding the repeated computation in the process of PSO algorithm, and saving a lot of time to make the algorithm fast convergence.

In conclusion, the EPL of dynamic PSO algorithm is suitable for calculating the virtual resistance values in different rotor speeds and different voltage swells. In practical application, the virtual resistance can be selected according to the current rotor speed and voltage swell.

\section{Simulation Results}

Simulations were performed using MATLAB based on the system configuration shown in Figure 2. The current study uses $2 \mathrm{MW}$ DFIG as the prototype to conduct simulation studies to verify the correctness of the aforementioned theoretical analysis. The main parameters of DFIG in the simulation are as follows: the stator inductance $L_{s}=0.0125 \mathrm{H}$, the rotor inductance $L_{r}=0.0126 \mathrm{H}$, the mutual inductance $L_{m}=0.0123 \mathrm{H}$, the stator winding resistance $R_{s}=0.0043 \Omega$, and the rotor winding resistance $R_{r}=0.0041 \Omega$.

Figures 9-11 are simulation waveforms of rotor current $q$ axis component $i_{r q}$, rotor voltage $v_{r q}$, A-phase rotor current $i_{r a}$ that used damping, respectively, when the amplitude of grid voltage swell are $1.3 \mathrm{pu}$ and the fault duration is $100 \mathrm{~ms}$. In Figure 9, the three-phase grid voltage swells to $130 \%$ of its normal value for $100 \mathrm{~ms}$ and thus induces big dc component in the stator flux linkage, which will result in the high rotor current; the oscillation amplitude of the rotor current in the grid voltage is higher than the amplitude of the rotor current in the grid voltage swells, because the point of grid voltage swells is uncertain. It can be seen from Figure 9 to Figure 11 that the use of damping control has a more obvious inhibition effect on the rotor current, and the rotor voltage does not exceed the upper limit voltage when failure amplitude is maximum. When the grid voltage swells, with the rising of the value of virtual resistance, the value of rotor current decreases and the value of rotor voltage increases. It can play a role of suppression of rotor current, and at the same time, the rise of the rotor voltage would threaten the safety of the converter.

\section{Experimental Results}

Experimental tests of the virtual resistance control strategy were performed on a laboratory setup of the $11 \mathrm{Kw}$ DFIG system to further verify the effectiveness of the proposed strategy. A $15 \mathrm{Kw}$ AC motor driving the DFIG at desired speed was used to emulate wind turbine. A TMS320LF28335 DSP was employed to control the rotor side converter and the grid side converter. The switching frequency for both converters was set at $5 \mathrm{kHz}$, with a sampling frequency of $10 \mathrm{kHz}$. PM100CLA120 was used for the switching device. The waveforms are acquired by a DPO4032 digital oscilloscope.

The main parameters of DFIG are as follows: the stator resistance $R_{s}=0.2858 \Omega$, the rotor resistance $R_{r}=0.2983 \Omega$, the stator leakage reactance $L_{s}=0.001323 \mathrm{H}$, the rotor leakage reactance $L_{r}=0.001781 \mathrm{H}$, and excitation reactance $L_{m}=0.0676 \mathrm{H}$.

Figures 12-14 show the experimental waveforms of the $q$ axis rotor current component $i_{r q}, q$ axis rotor voltage component $v_{r q}$, and A-phase rotor current $i_{r a}$ as the DFIG undergoes subsynchronization, synchronization, and supersynchronization. When the grid voltage three-phase symmetrical swell is $30 \%$, the fault duration is $100 \mathrm{~ms}$, and the virtual resistance is $0.5 \mathrm{pu}$ and $1.5 \mathrm{pu}$. Increasing the virtual resistance more significantly inhibits the rotor current oscillation caused by the grid voltage swell on the control system. When the grid voltage recovers, the oscillation amplitude of the rotor current becomes higher than when the grid voltage swells because of the fault duration and the point of grid voltage recovery. If the point is cut off by the fault and the electromagnetic oscillation caused by the grid voltage swell has not yet stopped, the oscillation caused by grid recovery will have been superimposed on the previous one. The oscillation amplitude of the rotor current under the super-synchronized operation is higher than that in the subsynchronized operation. Because the rotor side induction voltage in the supersynchronized operation is higher than that in the subsynchronized operation under grid voltage swell, the generator power is greater with the higher motor speed. Controlling the virtual resistance increases the rotor voltage but reduces the rotor current oscillation. Therefore, the selection of virtual resistance should consider the inhibition of the converter rotor voltage. 


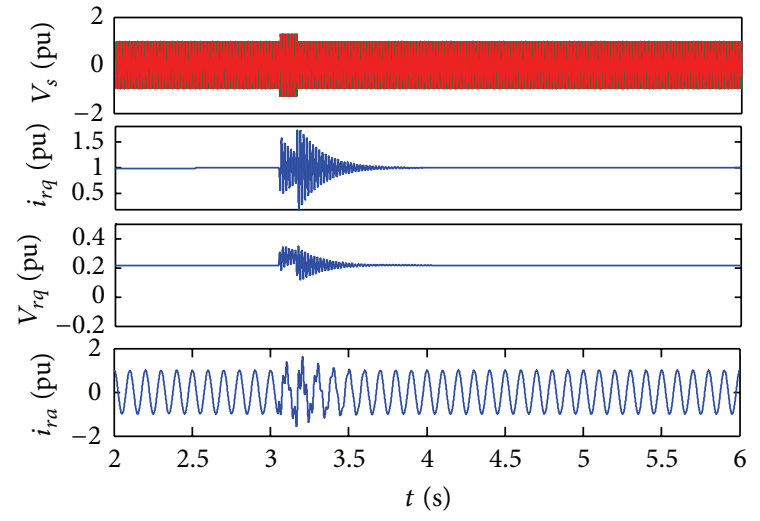

(a) Rotor current and voltage with 0.5 pu virtual resistance

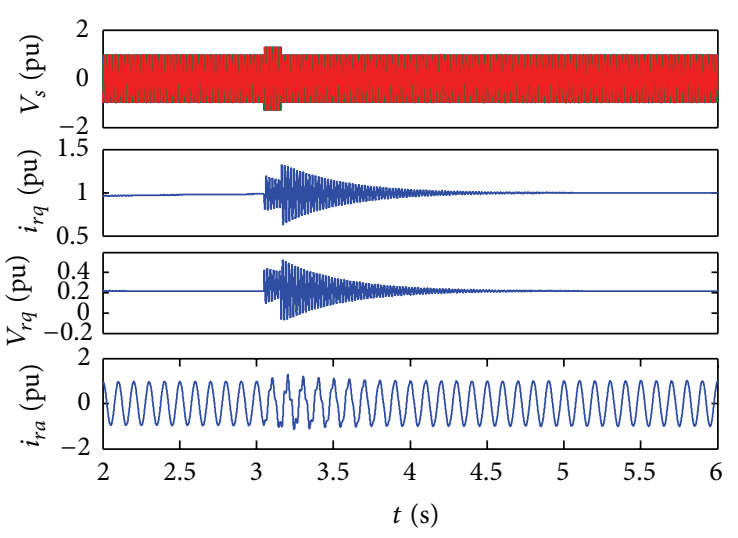

(b) Rotor current and voltage with 1.5 pu virtual resistance

FIGURE 9: Rotor current, voltage with variable damping control in subsynchronization.

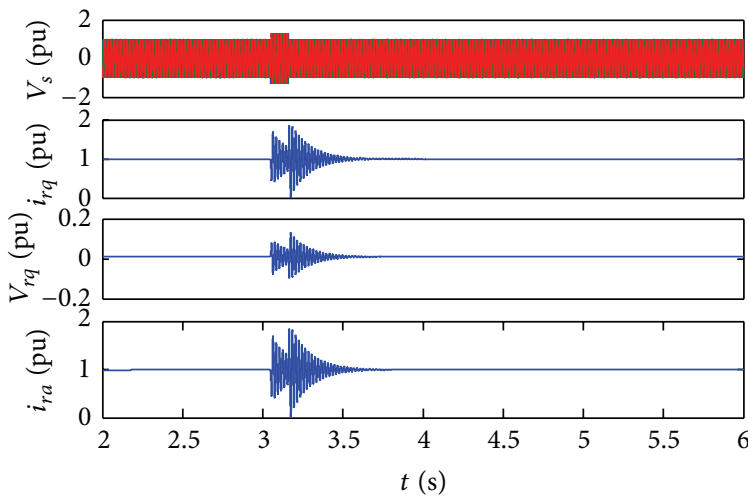

(a) Rotor current and voltage with 0.5 pu virtual resistance

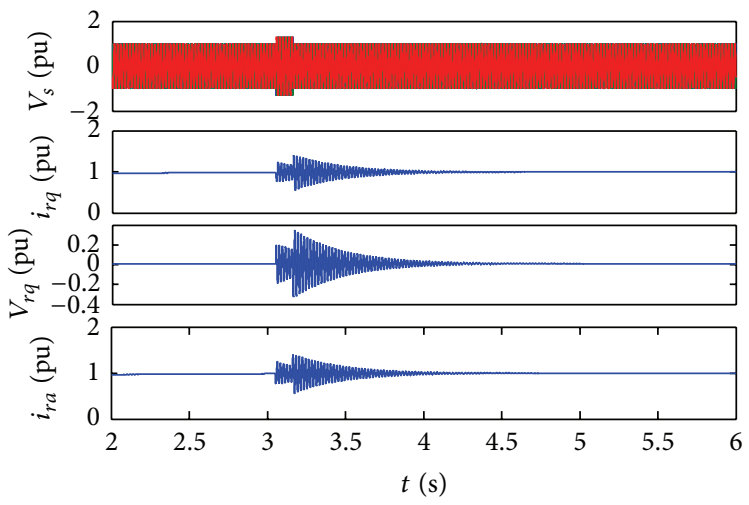

(b) Rotor current and voltage with $1.5 \mathrm{pu}$ virtual resistance

FIGURE 10: Rotor current, voltage with variable damping control in synchronization.

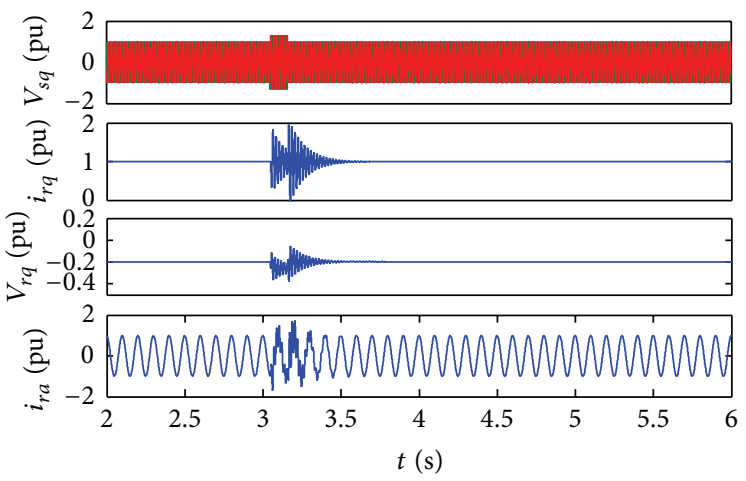

(a) Rotor current and voltage with 0.5 pu virtual resistance

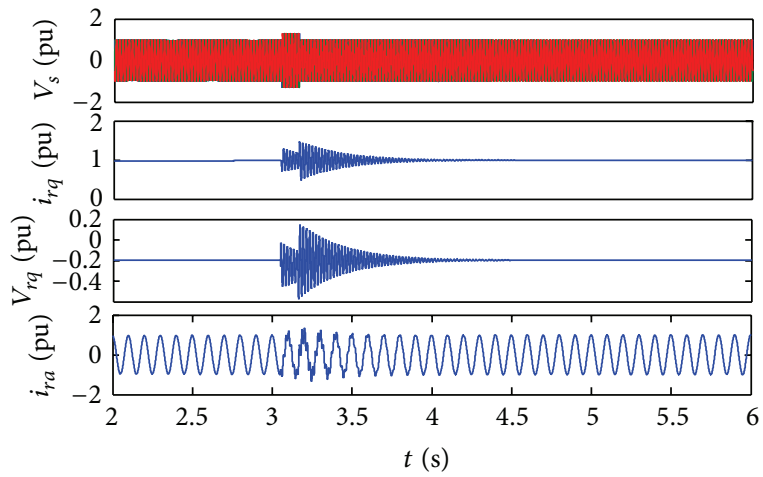

(b) Rotor current and voltage with 1.5 pu virtual resistance

FIGURE 11: Rotor current and voltage with variable damping control in supersynchronization.

\section{Conclusion}

This paper analyzes the DFIG electromagnetic transient process under a grid voltage swell, introduces active damping control to DFIG rotor excitation control based on passive damping control, and proposes an improved control strategy for variable damping and the acquisition of virtual resistances on the basis of the EPL of dynamic PSO algorithm. Due to the rapidity and accuracy of the algorithm, the virtual resistance value is more accurate. The control method based on active damping inhibited the rotor current oscillation caused by the grid voltage swell, reduced the effect of electromagnetic torque oscillation in the system during HVRT, and reduced the crowbar motion and its adverse effects. Variable damping 


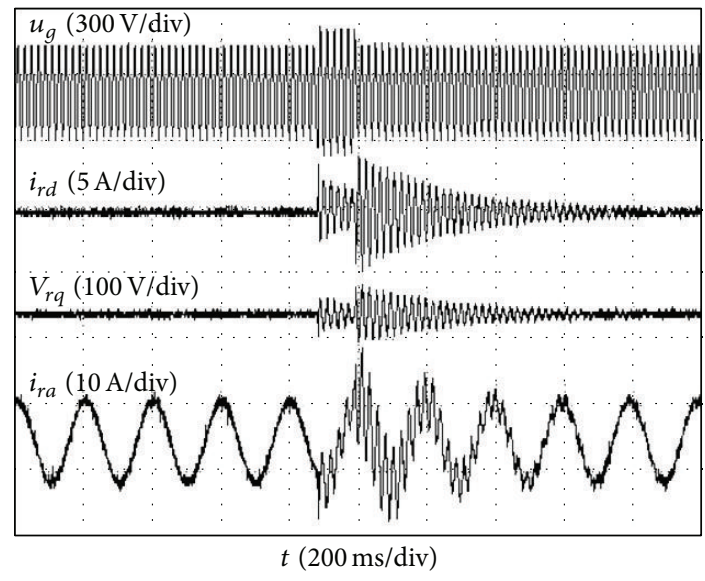

(a) Rotor current and voltage with 0.5 pu virtual resistance

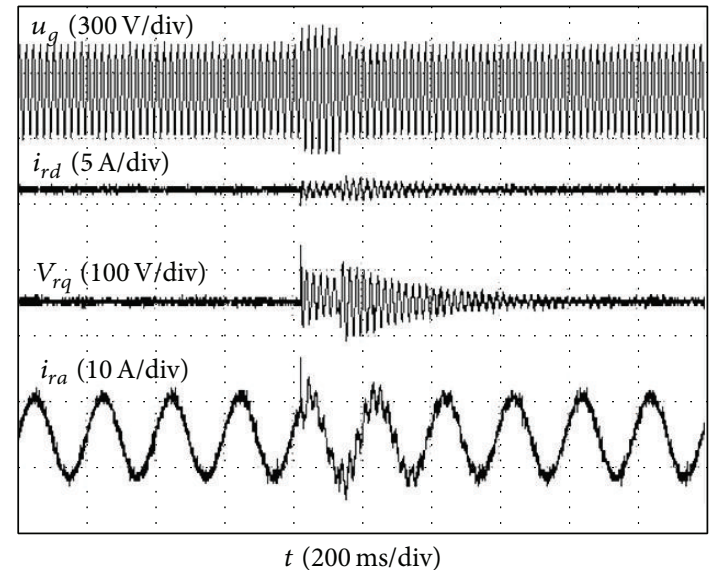

(b) Rotor current and voltage with 1.5 pu virtual resistance

FIGURE 12: Rotor current and voltage with variable damping coefficient in subsynchronization.

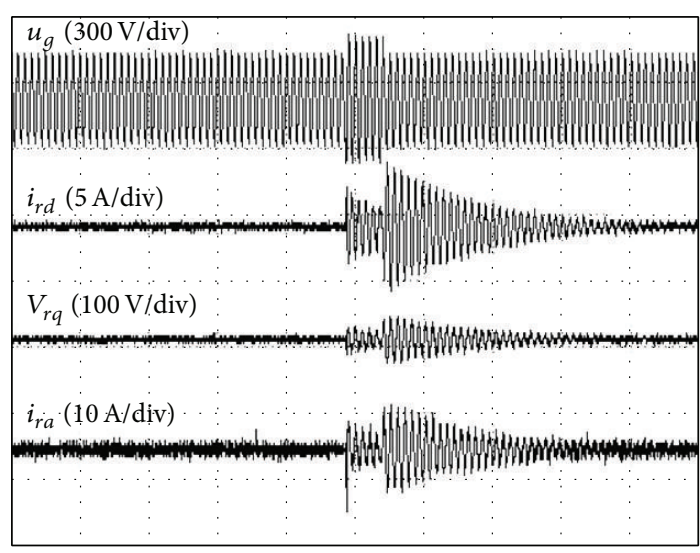

$t(200 \mathrm{~ms} / \mathrm{div})$

(a) Rotor current and voltage with 0.5 pu virtual resistance

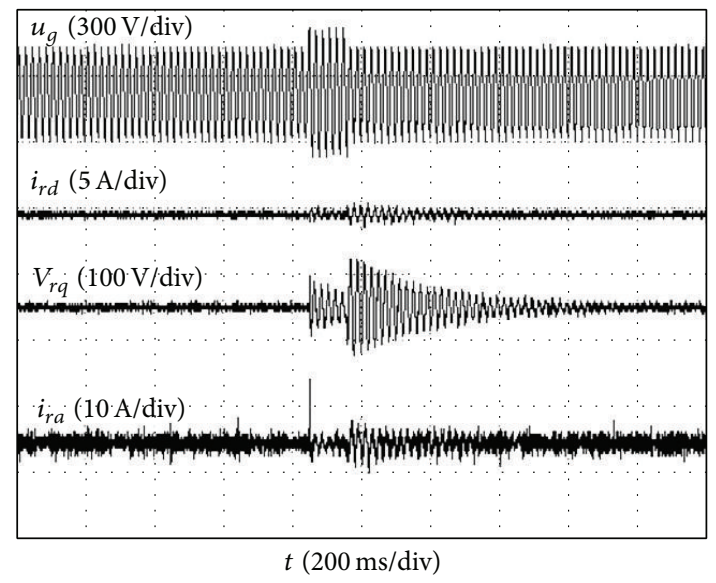

(b) Rotor current and voltage with 1.5 pu virtual resistance

FIGURE 13: Rotor current and voltage with variable damping coefficient in synchronization.

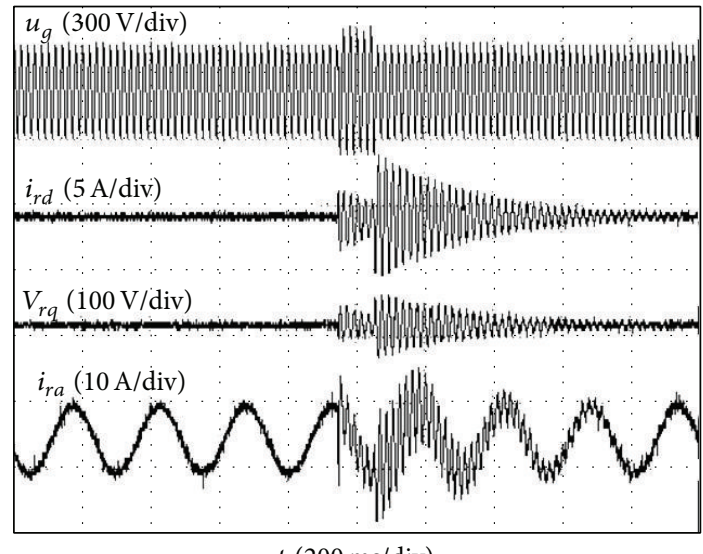

$t$ (200 ms/div)

(a) Rotor current and voltage with 0.5 pu virtual resistance

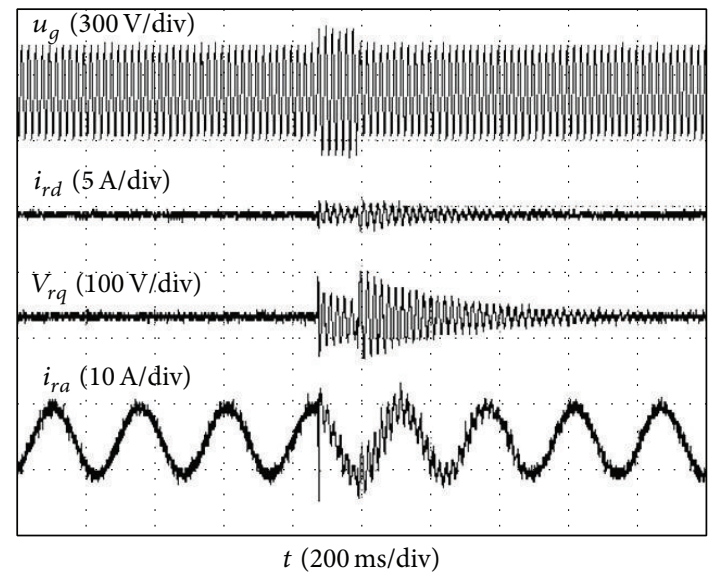

(b) Rotor current and voltage with 1.5 pu virtual resistance

FIGURE 14: Rotor current and voltage with variable damping coefficient in supersynchronization. 
control over the effect of different rotation speeds and the range of grid voltage swell in the system improved the HVRT control of DFIG.

\section{Conflict of Interests}

The authors declare that there is no conflict of interests regarding the publication of this paper.

\section{Acknowledgment}

The project was supported by National Natural Science Foundation of China (51277050).

\section{References}

[1] H. Nian, Y. Song, P. Zhou, and Y. He, "Improved direct power control of a wind turbine driven doubly fed induction generator during transient grid voltage unbalance," IEEE Transactions on Energy Conversion, vol. 26, no. 3, pp. 976-986, 2011.

[2] J. Hu, Y. He, L. Xu, and B. W. Williams, "Improved control of DFIG systems during network unbalance using PI-R current regulators," IEEE Transactions on Industrial Electronics, vol. 56, no. 2, pp. 439-451, 2009.

[3] J. López, P. Sanchis, X. Roboam, and L. Marroyo, "Dynamic behavior of the doubly fed induction generator during threephase voltage dips," IEEE Transactions on Energy Conversion, vol. 22, no. 3, pp. 709-717, 2007.

[4] S. Xiao, G. Yang, H. Zhou, and H. Geng, "An LVRT control strategy based on flux linkage tracking for DFIG-based WECS," IEEE Transactions on Industrial Electronics, vol. 60, no. 7, pp. 2820-2832, 2013.

[5] H. Geng, C. Liu, and G. Yang, "LVRT capability of DFIGbased WECS under asymmetrical grid fault condition," IEEE Transactions on Industrial Electronics, vol. 60, no. 6, pp. 24952509, 2013.

[6] J. P. da Costa, H. Pinheiro, T. Degner, and G. Arnold, "Robust controller for DFIGs of grid-connected wind turbines," IEEE Transactions on Industrial Electronics, vol. 58, no. 9, pp. 40234038, 2011.

[7] O. Abdel-Baqi and A. Nasiri, "A dynamic LVRT solution for doubly fed induction generators," IEEE Transactions on Power Electronics, vol. 25, no. 1, pp. 193-196, 2010.

[8] S. Müller, M. Deicke, and R. W. de Doncker, "Doubly fed induction generator systems for wind turbines," IEEE Industry Applications Magazine, vol. 8, no. 3, pp. 26-33, 2002.

[9] H. Zhou, G. Yang, and J. Wang, "Modeling, analysis, and control for the rectifier of hybrid HVdc systems for DFIG-based wind farms," IEEE Transactions on Energy Conversion, vol. 26, no. 1, pp. 340-353, 2011.

[10] B. C. Rabelo, W. Hofmann, J. L. da Silva, R. G. de Oliveira, and S. R. Silva, "Reactive power control design in doubly fed induction generators for wind turbines," IEEE Transactions on Industrial Electronics, vol. 56, no. 10, pp. 4154-4162, 2009.

[11] G. Iwanski and W. Koczara, "DFIG-based power generation system with UPS function for variable-speed applications," IEEE Transactions on Industrial Electronics, vol. 55, no. 8, pp. 3047-3054, 2008.

[12] N. Patin, E. Monmasson, and J.-P. Louis, "Modeling and control of a cascaded doubly fed induction generator dedicated to isolated grids," IEEE Transactions on Industrial Electronics, vol. 56, no. 10, pp. 4207-4219, 2009.

[13] A. Luna, F. K. de Araujo Lima, D. Santos, P. Rodríguez, E. H. Watanabe, and S. Arnaltes, "Simplified modeling of a DFIG for transient studies in wind power applications," IEEE Transactions on Industrial Electronics, vol. 58, no. 1, pp. 9-20, 2011.

[14] K. Rothenhagen and F. W. Fuchs, "Current sensor fault detection, isolation, and reconfiguration for doubly fed induction generators," IEEE Transactions on Industrial Electronics, vol. 56, no. 10, pp. 4239-4245, 2009.

[15] F. Bonnet, P. E. Vidal, and M. Pietrzak-David, "Dual direct torque control of doubly fed induction machine," IEEE Transactions on Industrial Electronics, vol. 54, no. 5, pp. 2482-2490, 2007.

[16] J. López, E. Gubía, E. Olea, J. Ruiz, and L. Marroyo, "Ride through of wind turbines with doubly fed induction generator under symmetrical voltage dips," IEEE Transactions on Industrial Electronics, vol. 56, no. 10, pp. 4246-4254, 2009.

[17] Z. Xie, Q. Shi, H. Song, X. Zhang, and S. Yang, "High voltage ride through control strategy of doubly fed induction wind generators based on active resistance," in Proceedings of the IEEE 7th International Power Electronics and Motion Control Conference (IPEMC '12), pp. 2193-2196, IEEE, Harbin, China, June 2012. 


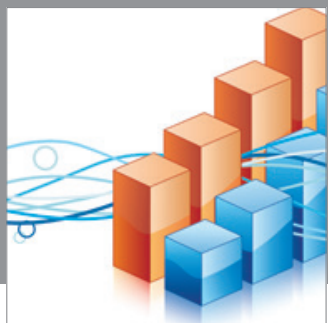

Advances in

Operations Research

mansans

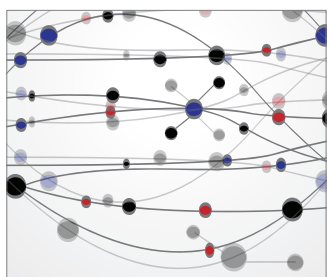

The Scientific World Journal
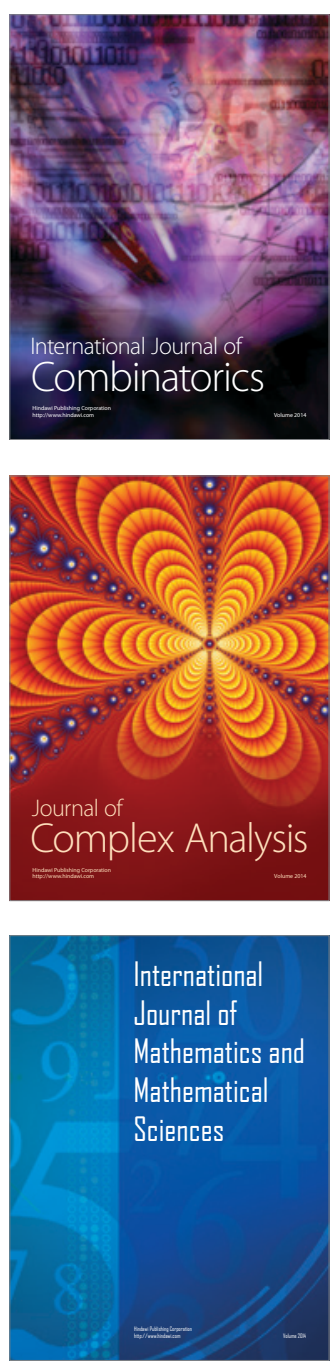
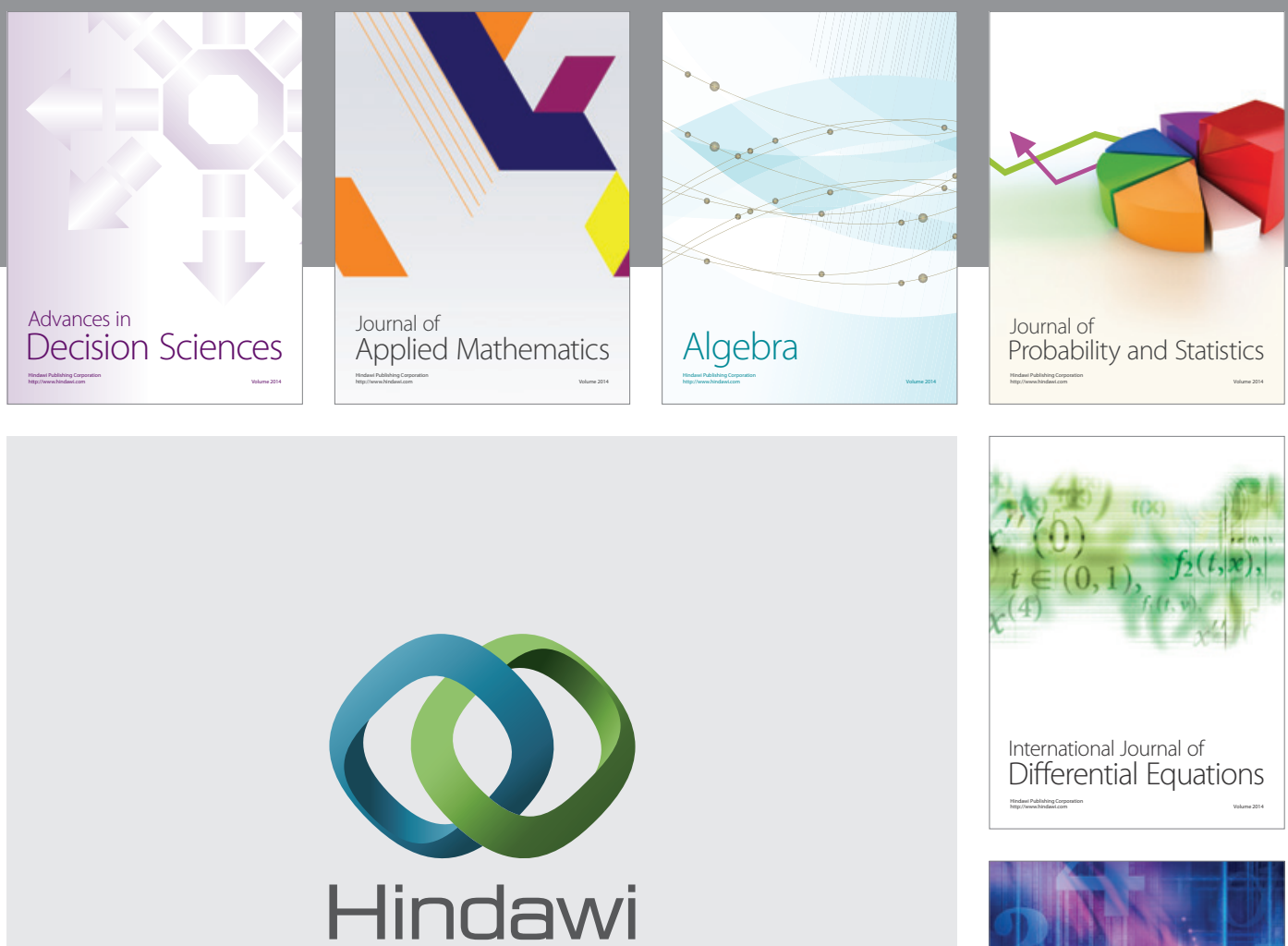

Submit your manuscripts at http://www.hindawi.com
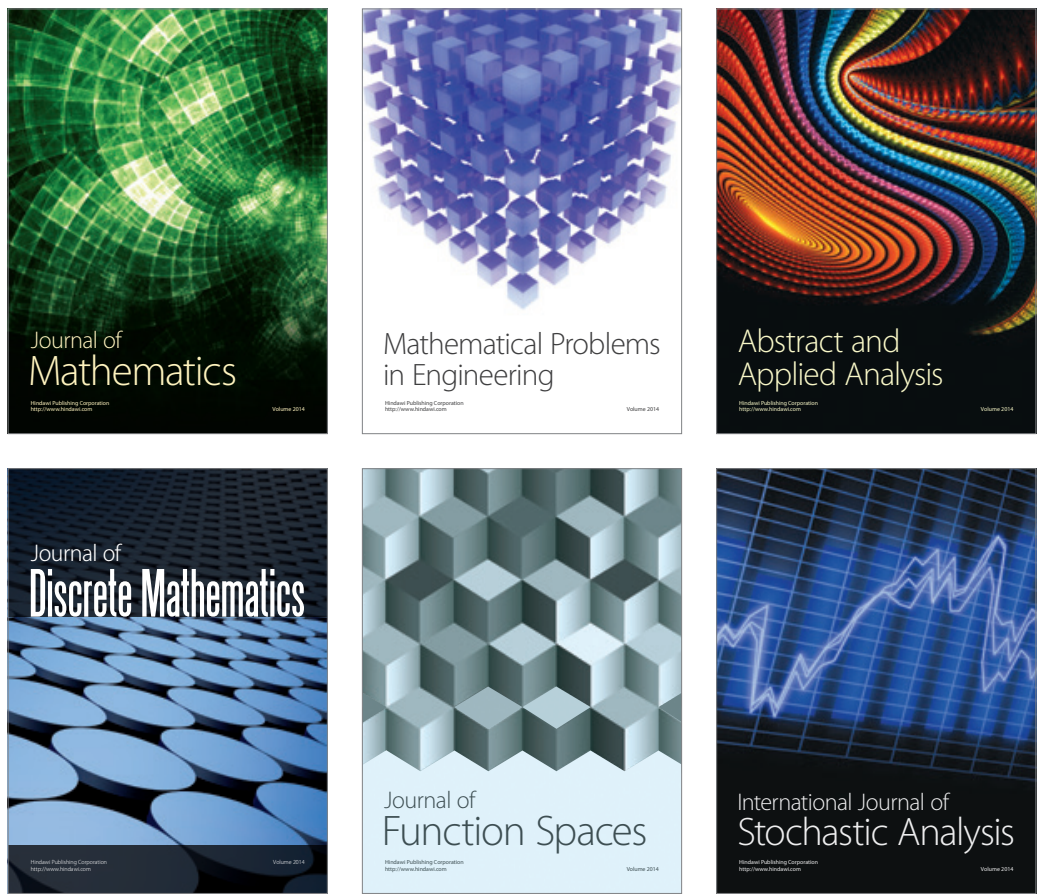

Journal of

Function Spaces

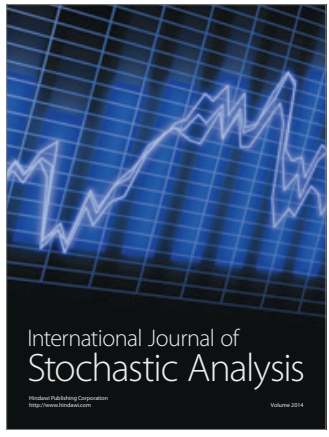

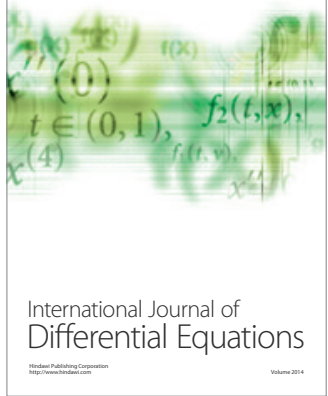
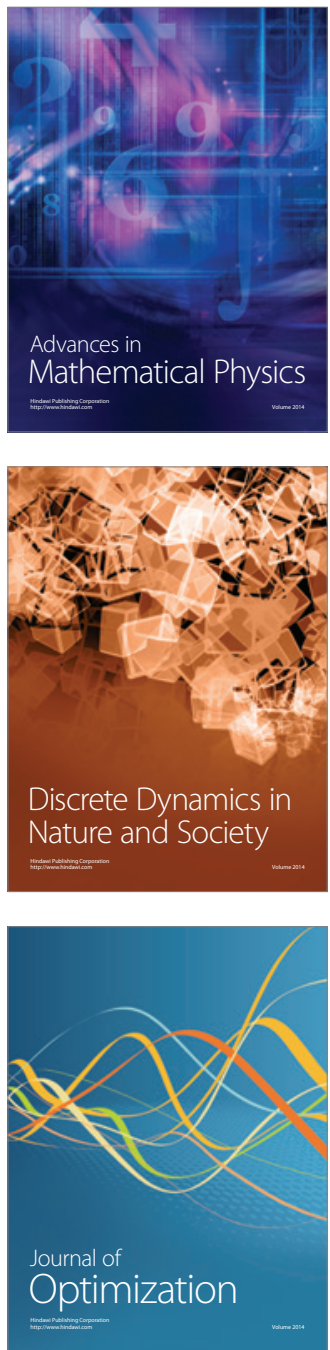